\title{
PROPOSTA DE SUBSTITUIÇÃO DE COPOS PLÁSTICOS DESCARTÁVEIS EM FÁBRIÇA DE GRANDE PORTE
}

\author{
MOTION FOR REPLACEMENT OF DISPOSABLE PLASTIC CUPS IN A LARGE FACTORY
}

\author{
Maria Eugenia Ramos May Corrêa, pós-graduanda (UTFPR) \\ Adriano Heemann, Dr. (UFPR) \\ Palavras Chave \\ Copos plásticos descartáveis; sustentabilidade; poliestireno; polipropileno
}

\section{Key Words}

Disposable plastic cups; sustainability; polystyrene; polypropylene

\section{RESUMO}

Tendo em vista o impacto ambiental gerado pela produção de copos plásticos descartáveis e a quantidade de resíduos gerada pelo uso desses produtos, o estudo aqui relatado tem como objetivo apresentar uma alternativa para a substituição de copos plásticos em uma fábrica na região de Curitiba. Por meio da pesquisa bibliográfica inicial é possível identificar as alternativas já existentes e, assim, adequá-las como uma solução pertinente para este caso específico. A proposta apresentada explora a substituição dos copos plásticos descartáveis por copos permanentes, de polipropileno, copos plásticos biodegradáveis, além da adoção de uma campanha visando à conscientização dos funcionários. $\mathrm{O}$ artigo discute essas possibilidades e aponta para perspectivas futuras.

\section{ABSTRACT}

In view of the environmental impact generated by the production of disposable plastic cups and the amount of waste generated by the use of these products, the study reported presents an alternative to the replacement of plastic cups at factory in Curitiba's region. Through an initial literature search it is possible identify existing alternatives and adapt them as an appropriate solution to this specific case. The proposal explores the replacement of disposable plastic cups for

permanent cups, made by polypropylene, biodegradable plastic cups and the adoption of campaign to raise awareness of employees. The article discusses these possibilities and points to future prospects. 


\section{INTRODUÇÃO}

É de conhecimento geral que o meio ambiente tem sido alterado mais fortemente desde a Revolução Industrial, porém, atualmente, as empresas estão cada vez mais conscientes de que precisam funcionar de forma sustentável, tornando-se corresponsáveis por seus produtos e por sua cadeia produtiva.

A sustentabilidade é uma característica de um sistema que permite a continuidade de suas atividades e do seu entorno por um período. $\mathrm{O}$ termo sustentabilidade não se refere apenas às preocupações ambientais, mas a todos os aspectos que se relacionam com o homem, como as questões econômicas, energéticas, sociais e culturais. Assim, ela também pode ser considerada a capacidade de interação do ser humano com o mundo.

O aumento da preocupação com a sustentabilidade ficou mais evidente a partir de estudos da década de 1970, que apontam que as ações humanas estariam gerando impacto ambiental com significativas alterações no meio ambiente e comprometendo a disponibilidade dos recursos naturais e a qualidade de vida atual e futura do homem. Atualmente, as empresas têm investido em recursos para minimizar os impactos ambientais causados em seu processo produtivo. No Brasil, os investimentos em processos, novas tecnologias e soluções alternativas orientadas à integração ambiental puderam ser mais visíveis a partir dos anos 2000. Segundo Vilhena e Politi (2000), alguns dos benefícios percebidos pela preocupação com a sustentabilidade é a recuperação de insumos, a diminuição dos desperdícios e o aumento do valor agregado ao processo em toda a cadeia produtiva. Outro benefício observado é o alcance de um diferencial diante de outras empresas do mercado, por meio do assim chamado marketing verde, utilizando um posicionamento ambiental melhorado como vantagem para os consumidores e tornando a empresa mais atrativa.

Parte da responsabilidade ambiental de uma fábrica também se refere ao gerenciamento dos resíduos gerados. Uma fábrica de produtos médicos de grande porte, localizada na região de Curitiba, oferece a seus 490 funcionários três refeições diárias, por turno, durante as quais todas as bebidas são servidas em copos plásticos descartáveis. Cabe observar, entretanto, que estes são usados sem restrições também durante todo o expediente. De maneira geral, os copos são utilizados uma vez e descartados em seguida.

O impacto ambiental causado pelo descarte dos copos plásticos poderia ser minimizado pela substituição destes. Uma substituição desse tipo pode culminar na redução do uso de matéria-prima para sua fabricação (petróleo), na redução de custos relativos à compra de copos novos, ao descarte dos usados, entre outros.

A partir desse cenário, este projeto tem por objetivo apresentar e avaliar qualitativamente a pertinência da substituição dos copos plásticos descartáveis por outra opção adequada à realidade da empresa e que evidencie seu papel responsável na gestão de resíduos perante seus funcionários e à sociedade de um modo geral. $\mathrm{O}$ objetivo deste trabalho não é o de exaurir esse complexo assunto, propor uma solução necessariamente mais barata ou ainda anular impactos ambientais. $\mathrm{O}$ estudo aqui apresentado cogita uma ação mais alinhada com a estratégia de sustentabilidade industrial.

\section{DESENVOLVIMENTO}

O consumo de copos descartáveis gera um volume alto de resíduos diários principalmente porque, em geral, os copos são utilizados uma única vez e descartados em seguida. A quantidade de resíduos gerada pela empresa poderia ser minimizada pela substituição destes.

Um dos principais aspectos ambientais a serem considerados na decisão de utilizar os copos plásticos descartáveis é a sua matéria-prima, o petróleo, que é uma fonte não renovável. Além disso, a produção de produtos derivados do petróleo pode gerar vários riscos para o meio ambiente, por exemplo, o petróleo retirado de plataformas marítimas, cujo contato com a água do mar é altamente danoso, pois afeta o ecossistema, provocando contaminações e a morte de animais e plantas.

Contudo, o consumo de copos plásticos descartáveis é facilitado pelo baixo custo de compra e pela grande quantidade de oferta desse produto no mercado. Esse contexto problemático é descrito de modo sumarizado nas seções que seguem.

\subsection{Copos descartáveis}

Atualmente o estilo de vida é influenciado pela praticidade propiciada pelos produtos plásticos. Esse material está presente em diversos produtos do cotidiano como pentes, seringas, painéis, botões, espumas, lanternas, borrachas, utensílios domésticos, embalagens etc.

Segundo Eco (2016), são consumidos no Brasil aproximadamente 720 milhões de copos plásticos descartáveis por dia, o que corresponde a cerca de 1.500 toneladas de resíduos por dia.

A fabricação dos copos plásticos se dá por meio do processo de termoformação. Nesse processo, os pellets de poliestireno (matéria-prima) são carregados em uma máquina extrusora, que os aquece até o seu derretimento 
e, por meio de uma força, gera um filme de plástico rígido e com aproximadamente dois milímetros de espessura. $\mathrm{O}$ filme passa através de um forno até que o plástico torne-se maleável. O plástico então passa por uma máquina de termoformação que puxa e suga-o na cavidade do molde até que ele preencha toda a forma do molde. São realizadas várias fileiras de copos simultaneamente e esse processo demora aproximadamente três segundos. Os copos então são transferidos para uma máquina que corta os copos da folha. Essa máquina capta os restos da folha e os derrete transformando-os novamente em plástico que são reutilizados na produção de novas folhas. Depois do corte, os copos são encaminhados para outra máquina que os empilha e os envia, em grupos, para uma esteira que os encaminha para uma máquina com capacidade de aquecimento o suficiente apenas torná-los flexíveis e realizar a dobra das bordas dos copos, tornando-as arredondadas.

Para a fabricação de um copo plástico são necessários aproximadamente oito gramas de poliestireno. O consumo de energia elétrica é de cerca de $6,0 \mathrm{~W} / \mathrm{h}$ por copo.

Os copos plásticos descartáveis têm como matéria-prima o poliestireno, obtida por meio de reações químicas do estireno, um derivado do petróleo, que é uma fonte não renovável de matéria-prima. A decomposição dos produtos fabricados em poliestireno é lenta, pois não são biodegradáveis (não são decompostos por micro-organismos) e, por isso, considera-se que o seu tempo de meia vida é longo. O tempo de decomposição de um copo descartável pode durar entre 50 e 400 anos dependendo das condições ambientais, enquanto que a vida útil dos copos chega a ser de apenas 13 segundos após sair do display.

Esse dado aponta para a relevância do tema quando considerado o seu aspecto ambiental. Para Canto (2001), o consumo de copos descartáveis é exagerado. A escolha indiscriminada por copos descartáveis acontece, sobretudo, devido ao relativo conforto e higiene proporcionados ao consumidor, uma vez que não exige o gasto de tempo e recursos com lavagem.

O poliestireno é considerado uma matéria-prima barata. Portanto, no que tange ao aspecto comercial sua reciclagem a partir de copos descartados não se apresenta economicamente viável. O poliestireno reciclado é pouco empregado, pois o valor pago pelas empresas e cooperativas de reciclagem varia entre $\mathrm{R} \$ 0,20$ e $\mathrm{R} \$ 1,00$ por quilo (SUSTENTÁVEL, 2016). Ao baixo preço pago pelo material são adicionadas as dificuldades da reciclagem do resíduo. Portanto, nesse caso a reciclagem de copos plásticos descartáveis é considerada mais dispendiosa que a produção dos copos a partir da matéria-prima virgem.
A reciclagem geralmente é feita por meio do derretimento e da remodelagem. Segundo Canto (2001), apenas 87\% dos polímeros do mercado são termoplásticos, ou seja, podem ser derretidos e remodelados. Outra dificuldade da reciclagem está na incompatibilidade entre os diferentes tipos de plásticos que ainda podem estar misturados no momento do processamento. Segundo o autor, 30\% do volume de lixo sólido correspondem a produtos plásticos, além da grande quantidade, a baixa velocidade de degradação culmina em um grande acúmulo de resíduos.

\subsection{Problemática}

Uma fábrica de produtos médicos de grande porte, localizada na região de Curitiba possui 490 funcionários, destes, 170 são dos setores administrativos e recebem por dia dois cafés e uma refeição, e, para os 320 funcionários da produção, são oferecidos um café e uma refeição por dia. No total, são servidos diariamente, aproximadamente, 810 cafés e 530 refeições.

Nessa empresa as refeições (almoço e ceia) são servidas com talheres (garfos, facas e colheres) de aço inox, com pratos de cerâmica ou de material polimérico (pratos de sopa), e acompanhados por copos plásticos descartáveis $(200 \mathrm{~mL})$ e guardanapos de papel.

Durante todas as refeições os talheres e pratos são disponibilizados no início do buffet, os copos plásticos ficam disponíveis junto às bebidas, no final do buffet, e os guardanapos são disponibilizados em porta-guardanapos nas mesas.

Como as bebidas e os copos plásticos são disponibilizados no fim do buffet, é comum entre os funcionários pegar mais de um copo por vez, evitando com que tenham que se deslocar para pegar mais bebidas. Com relação aos utensílios, há reposição ininterrupta dos itens para os funcionários que estão utilizando o refeitório.

Na empresa estudada, os funcionários são estimulados a fazer a separação do lixo durante todo o expediente, inclusive durante as refeições. No refeitório, os guardanapos e os copos plásticos devem ser descartados em lixeiras específicas para cada um deles. Os pratos e talheres são colocados em uma janela, que faz passagem para a sala em que são lavados.

Os copos plásticos descartáveis $(200 \mathrm{~mL}$ ) também são usados livremente durante o expediente, por todos os funcionários, para o consumo de bebidas como café, água e chá, o que faz com que a quantidade utilizada de copos seja significativamente maior do que a de louças usadas apenas durante as principais refeições. Os suportes de copos plásticos, disponíveis em vários ambientes da empresa, são abastecidos pela equipe de limpeza da 
empresa. Ao lado de cada suporte estão disponíveis lixeiras próprias para esse tipo de resíduo, para auxiliar o descarte seletivo (Figura 1).

Figura 1 - Bebedouro e display utilizados pela empresa
Figura 2 - Lavadora Hobart Ecomax 900

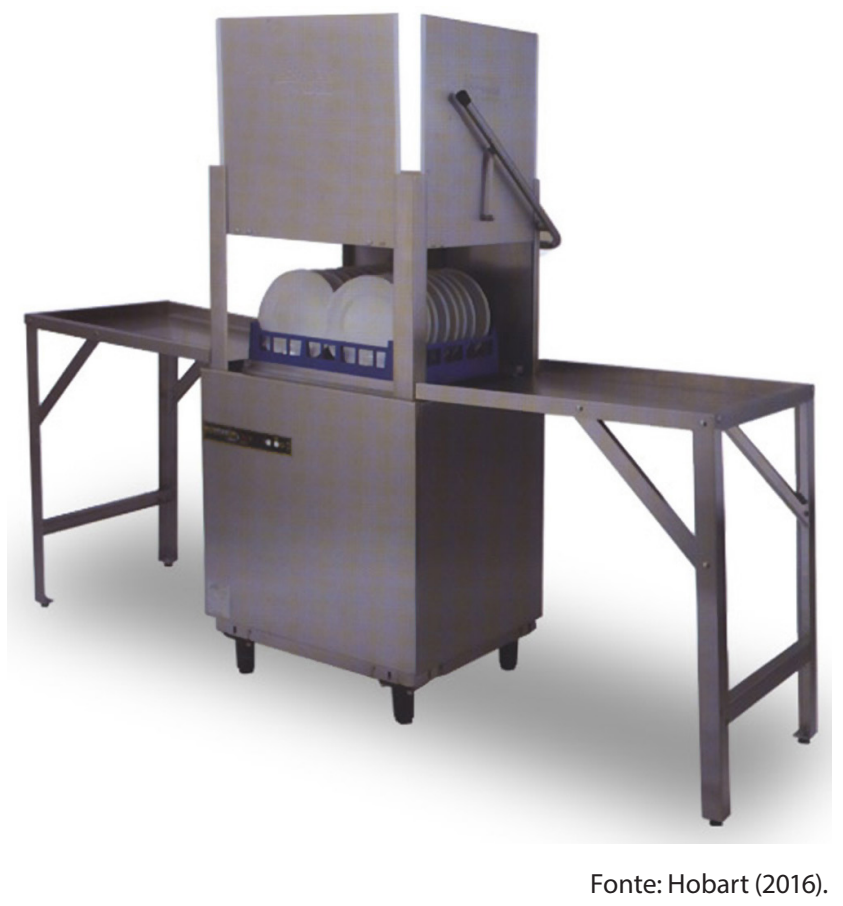

O primeiro turno da empresa concentra a maior quantidade de funcionários, por isso, são precisos três funcionários para realizar a limpeza da louça. Nos outros dois turnos, um funcionário é responsável pela limpeza. Para realizá-la, os funcionários devem:

1. Separar cada tipo de utensílio;

2. Retirar o excesso de sujeira com água corrente e detergente neutro;

3. Colocar a louça nos racks;

4. Colocar os racks na máquina;

5. Colocar o detergente na máquina;

6. Ligar a máquina (o ciclo de lavagem leva em torno de 1 minuto);

7. Retirar a louça da máquina e revisar a lavagem, item a item;

8. Repor a louça no buffet.

A lavadora possui ajuste de ciclos de lavagem, sendo que a configuração Standart é de um minuto (os outros são ajustáveis pelo operador), o consumo de água é de 228 litros por hora ou, de aproximadamente 3,8 litros por ciclo. O gasto elétrico dessa lavadora é de $18 \mathrm{~kW} / \mathrm{h}$.

Ela possui uma capacidade mecânica de limpeza de 60 ciclos por hora. Sendo que, cada ciclo comporta 18 pratos, 160 talheres, nove bandejas ou entre 25 e 36 copos.

Considerando que são servidas 530 refeições por dia e 810 cafés, a lavadora é utilizada, em média, 110 vezes por dia. Para tal cálculo considerou-se 30 ciclos de lavagem para os pratos de cerâmica, cinco para pratos poliméricos, 15 para ta-

Iheres e 60 ciclos de lavagem para as bandejas.

\subsection{A louça na empresa}

Os talheres e pratos são lavados na empresa por meio da máquina lavadora Hobart Ecomax 900, ilustrada na Figura 2. 
Para a utilização da lavadora de louças são consumidos pela empresa água, detergente, energia e horas-homem de trabalho.

\subsection{Gestão de louças, copos e guardanapos}

Os copos plásticos utilizados pela empresa são adquiridos de dois modos diferentes, pela própria empresa, para uso geral e pela empresa terceirizada, fornecedora das refeições, para uso no refeitório.

Na fábrica são consumidos aproximadamente 42.500 copos por mês. Já a quantidade de copos utilizados no refeitório é de aproximadamente 40.000 unidades por mês, totalizando um consumo aproximado de 82.500 copos descartáveis por mês. A compra dos copos plásticos pela própria fábrica é realizada anualmente. A compra para consumo no ano de 2016 foi de $\mathrm{R} \$ 13.500,00$.

A compra de guardanapos de papel é de responsabilidade da empresa encarregada pelas refeições. Nesse caso, são comprados 14 mil guardanapos por semana, o que corresponde a uma média de 56 mil guardanapos por mês. A seleção de talheres de aço inox acontece por causa da qualidade da matéria-prima, que permite diferentes aplicações, é resistente ao processo de limpeza (corrosão) e possui um longo tempo de vida útil.

Já a seleção dos copos de plástico e dos guardanapos de papel ocorre em razão da facilidade de compra e baixo custo para obtenção desses materiais. Além disso, não exigem a etapa da higienização. Tanto os copos plásticos descartáveis quanto os guardanapos de papel são descartados em lixos específicos e então são entregues a empresas terceirizadas que fazem a coleta específica desse tipo de material. Os copos são entregues juntamente com todos os resíduos plásticos da fábrica, sendo então submetidos a tratamento e descarte. Os guardanapos de papel são descartados pela empresa responsável pela coleta em um aterro Classe II.

Na fábrica toda a água utilizada tanto na produção, quanto para consumo interno e na cozinha é retirada de poços artesianos. O consumo médio mensal de água fornecida pela companhia de abastecimento é de aproximadamente $60 \mathrm{~m} 3$ por mês, essa água é utilizada especificamente para uma máquina. Após o uso, toda água utilizada (tanto de origem de poços artesianos, quanto a fornecida pela companhia de abastecimento) é tratada internamente e despejada no rio localizado nas imediações da empresa.

\subsection{Proposta de substituição no refeitório}

A substituição dos copos plásticos descartáveis no refeitório por copos reutilizáveis poderia diminuir os resíduos gerados em aproximadamente 40 mil unidades por mês. Segundo o fabricante, a lavadora Ecomax 900 tem capacidade de limpeza de 60 racks por hora. A lavadora, em seu maior horário de uso (almoço) é utilizada aproximadamente 89 vezes ( 25 ciclos de lavagem para os pratos de cerâmica, quatro para pratos poliméricos, 10 para talheres e 50 ciclos de lavagem para as bandejas). Considerando que a louça não precisa ser lavada imediatamente após o uso, é possível substituir os copos plásticos descartáveis utilizados na hora das refeições por copos permanentes.

Para a substituição dos copos plásticos descartáveis, existem no mercado opções de copos de vidro, cerâmica, inox, polipropileno. Devido à fragilidade dos materiais das duas primeiras opções, a terceira e quarta opções se mostram mais pertinentes para um uso diário e em grande quantidade.

Copos e canecas em polipropileno são resistentes a quedas e impactos e apresentam elevada durabilidade. O copo em polipropileno é inodoro, atóxico, resistente a sucos cítricos e bebidas quentes, além de ser produzido com uma matéria-prima que conserva a temperatura das bebidas por mais tempo. Pode ser usado em lava-louças. Além disso, o polipropileno é um termoplástico polimerizado por meio do gás propileno, derivado do propeno, e é reciclável. Ele é um tipo de plástico que pode ser moldado apenas por meio do aquecimento.

Além do benefício ambiental, o uso de copos e canecas em polipropileno com capacidade de $370 \mathrm{~mL}$ geraria mais conforto para os funcionários, que não teriam que se deslocar tanto para repor as bebidas durante as refeições, fazendo com que os funcionários utilizassem menos copos por refeição. A quantidade de copos estimada para ser comprada pode ser a mesma da quantidade de pratos, pois se considera que o funcionário use um prato e um copo por refeição. Caso sejam consumidos mais copos do que pratos eles podem ser comprados em outro momento. Atualmente são usados 400 pratos no refeitório.

Esses copos e canecas poderiam ser higienizados na mesma lavadora de louças já utilizada pela empresa para limpar as louças do refeitório. A lavadora já mencionada possui racks para ciclos de lavagem de copos. Ela possui racks de polipropileno para acondicionamento de 25 copos, com engradado. Para tanto, também seriam consumidos a mais pela empresa água, sabão, energia e horas-homem de trabalho.

O rack compatível com a lavadora Ecomax 900, segundo o fabricante, tem capacidade entre 25 a 36 copos por ciclo, ou seja, considerando o mínimo da lavadora, para lavar 400 copos seriam necessários 16 ciclos de lavagem. Ponderando que sejam servidos 810 cafés e 530 refeições por dia, seria necessário realizar, aproximadamente, 54 
lavagens a mais por dia (pensando no uso de um copo por funcionário por refeição).

Para o uso de copos permanentes e utilização da lavadora é necessário rever o contrato com a empresa responsável pela alimentação, pois será necessária a realização de mais atividades. $\mathrm{O}$ uso de copos permanentes reduziria as horas-homem de trabalho para realizar a compra, o recebimento e a reposição desses produtos em seus displays.

\subsection{Substituição nos ambientes administrativos}

Para diminuir ainda mais a quantidade de resíduos gerada, pode ser realizada a substituição dos copos descartáveis por copos permanentes também nas áreas administrativas, nas quais é permitida a presença de bebidas. A substituição total ocorreria dentro de uma postura exemplar de comprometimento por parte da presidência. Atualmente, nas áreas administrativas há um total de 170 funcionários. Considerando uma média de três copos durante o expediente, isso corresponderia a uma redução de aproximadamente 510 copos por dia somente nessas áreas.

Os copos e as canecas utilizados nas áreas administrativas poderiam ser coletados pela empresa terceirizada, atualmente responsável pela limpeza, no final dos turnos, por meio de caixas coletoras. Então, os copos utilizados seriam higienizados na cozinha e devolvidos para o uso. Considerando o uso diário de apenas um copo durável por funcionário das áreas administrativas, isso representaria a adição de sete ciclos de lavagem pela máquina já existente na empresa.

\subsection{Copos ecológicos}

Para os departamentos em que os copos plásticos descartáveis eventualmente não possam ser substituídos por copos permanentes, é possível substituí-los pelos chamados copos ecológicos ou biodegradáveis. Um exemplo são os copos fornecidos pela empresa Ecopo (2016), disponibilizados em um formato inicial tipo envelope, com nove centímetros de altura por seis de comprimento e capacidade de 65 mililitros após aberto.

De acordo com Ecopo (2016), o principal benefício do consumo desse tipo de copo é que este é degradado em até 18 meses após o descarte. O produto é confeccionado em papel de fibras virgens sem corantes (para evitar qualquer tipo de contaminação do material), oriundo de reflorestamento certificado. Ainda, conforme as especificações do produto, cada copo pode ser utilizado mais de uma vez.

Devidoaoseuformato (envelope) esse tipo decopo pode ter o volume para armazenamento e transporte diminuído, tanto do copo novo quanto do descartado. Entretanto, é preciso considerar o custo de aquisição do copo para efeitos de substituição em larga escala. Atualmente, uma caixa com 4.000 unidades custa aproximadamente $\mathrm{R} \$$ 186,00 reais, tendo preço unitário de $\mathrm{R} \$ 0,46$.

\section{CONCLUSÃO}

Uma fábrica de grande porte localizada na região de Curitiba oferece a seus funcionários bebidas servidas em copos plásticos descartáveis durante as refeições e durante o expediente. Esses copos são utilizados uma única vez e descartados na sequência.

Por serem fabricados a partir de uma matéria-prima não renovável, o consumo despreocupado desses copos descartáveis pode ser interpretado como ausência de preocupação ambiental. Como discutido no presente artigo, o consumo desse tipo de copo, em larga escala, culmina em uma quantidade significativa de resíduos com um processo de decomposição longo. Nesse sentido, o presente estudo argumenta que o consumo de copos plásticos descartáveis não está alinhado com os esforços mundiais de sustentabilidade industrial.

A quantidade de resíduos gerada pelo consumo de copos descartáveis pode ser minimizada pela adoção de uma estratégia de substituição. A substituição de 100\% dos copos plásticos descartáveis no refeitório e nas áreas administrativas pode representar uma redução do consumo de aproximadamente 52 mil unidades por mês.

De acordo com a argumentação aqui apresentada, a substituição dos copos plásticos descartáveis por copos permanentes acarretaria em poucas alterações no fluxo de limpeza de louça na cozinha, uma vez que são itens que podem ser inseridos no mesmo ciclo de limpeza já utilizado para as outras louças. A inclusão de copos permanentes, além de não impactar em mudança significativa na rotina, representaria uma grande alteração na quantidade de resíduos gerada anualmente pela fábrica.

Cabe salientar que a adoção dessa estratégia de sustentabilidade demandaria a participação de toda a empresa e das empresas terceirizadas. Uma campanha permanente de conscientização de funcionários também seria necessária. Uma campanha desse tipo poderia contemplar informação, metas e brindes. $\mathrm{O}$ advento de copos permanentes também poderia ser estimulado caso estes fossem personalizados e oferecidos em diferentes cores e/ou modelos, com design diferenciado.

Finalmente, o artigo argumenta que a substituição dos copos plásticos descartáveis aqui proposta pode gerar a redução direta do uso de matéria-prima para sua fabricação (petróleo), redução de custos (menos copos comprados por mês), redução dos gastos com resíduosproduzidos 
pela fábrica, entre outros. Contudo, é possível admitir que esse caso pode, acima de tudo, repercutir como um impulso para a adoção dessa estratégia em outras atividades da empresa como, por exemplo, a diminuição do consumo de guardanapos, papel sulfite, tinta, tonner, energia elétrica, produtos de limpeza entre outros.

\section{AGRADECIMENTO}

Os autores agradecem à Fundação Araucária pelo apoio na forma de bolsas de estudos.

\section{REFERÊNCIAS}

VILHENA, A.;POLITI, E. Reduzindo, reutilizando, reciclando: a indústria ecoeficiente. São Paulo: CEMPRE - Compromisso Empresarial para Reciclagem: SENAI, 2000.

CANTO, E. L. do. Plástico: bem supérfluo ou mal necessário? São Paulo: Moderna, 2001.

HOBART. Hobart - Equipamentos Cozinha Industrial e Supermercados. Disponível em: <hobart.itwfeg.com. br>. Acesso em: 08/05/2016.

ECO. Meu copo eco. Disponível em: <www.meucopoeco.com.br>. Acesso em: 17/04/2016.

ECOCOPO. Copo descartável em formato de envelope. Disponível em: <www.ecopo.com.br>. Acesso em: 05/06/2016.

SUSTENTÁVEL. Site sustentável. Disponível em: $<$ http://inst.sitesustentavel.com.br/evite-usar-copos-descartaveis-na-sua-empresa>. Acesso em: 17/04/2016. 